\title{
Mean Platelet Volume in Acute Appendicitis a Case-Control Study
}

\author{
Alberto Robles Méndez Hernández ${ }^{1,2 *}$, Ulises Rodríguez Wong ${ }^{3}$, Gilberto Gerardo Ortiz \\ Cantú $^{2}$, Jorge Alfonso Pérez Castro y Vázquez ${ }^{2}$, Carlos Eduardo Rodríguez Rodríguez ${ }^{2}$, \\ Adriana Paz Mendoza ${ }^{2}$, Samantha Escorza Valdivia ${ }^{2}$, María Anota Rivera ${ }^{4}$ \\ ${ }^{I}$ Facultad Mexicana de Medicina, Universidad La Salle México, Mexico City, Mexico \\ ${ }^{2}$ General Surgery Department, Hospital Angeles Metropolitano, Mexico City, Mexico \\ ${ }^{3}$ ColorectalSurgery Department, Hospital Angeles Metropolitano, Mexico City, Mexico \\ ${ }^{4}$ Colorectal Surgery Department, Hospital General Regional No. 1 “Dr. Carlos Mac Gregor Sánchez”, Instituto \\ Mexicano del Seguro Social, , Mexico City, Mexico \\ *Corresponding Author: Alberto Robles Méndez Hernández, General Surgery Service, Hospital Ángeles \\ Metropolitano, Tlacotalpan \#59, Mexico City, Mexico.
}

\begin{abstract}
Background: Acute appendicitis is the main causeof surgical acute abdomen in productive ages, with their main incidence between 15 and 35 years. The mean platelet volume is currently considered as an acute phase reactant, it is considered an indicator inversely proportional to the process of systemic inflammatory response, it has been promoted as a biomarker-type study object with good diagnostic and prognostic potential for acute appendicitis processes
\end{abstract}

Material and Methods: The study was developed retrospectively between February 2018 and February 2020, comparing Mean Platelet Volume in male patient in ages between 15-35 years old in two groups. Appendicitis group confirmed by histopathology and their control group, patients admitted for elective inguinal hernia. Values of leukocytes, neutrophils, MPV, were used for their analysis. Statistical analysis was performed with X2 test for age and numbers ofleukocytes, neutrophil count, platelets and MPV.

Results: In the appendicitis group Pearson correlation was performed with control group: appendicitis with respect to leukocytes, neutrophils and MPV. Results: Statistically significant differences were found in leukocytes and MPV between the two groups. In the VPM values in the appendicitis group, an average of 8,2 \pm 0.93 is observed and in the control group, values of $9.2 \pm 1.15$ are observed with a statistically significant difference with $p<0.05$.

Conclusion: Although quite practical, there is insufficient evidence to recommend the systematic use od mean platelet volume as diagnostic criteria for acute appendicitis, multiples studies suggest its use with wide range sensibility.

Keywords: Acute appendicitis, mean platelet volume.

\section{INTRODUCTION}

Acute appendicitis (AA) is the main cause of surgical acute abdomen in productive ages, with their main incidence between 15 and 35 years. The AA incidence is 233 cases per 100,000 persons in one-year, while life risk disease is $8.6 \%$ for men and 6.7 for woman. $[1,2]$

Timely diagnosis is important to reduce morbility and mortality, the use of paraclinics in a systematic way resulting in the appropriate approach for the patient with abdominal pain under study.
The vermiform appendix is a vestigial organ, its average size covers $10 \mathrm{~cm}$ in its longitudinal diameter, however it can reach up to $30 \mathrm{~cm}$, with an axial diameter of up to $1 \mathrm{~cm}$. The clinical picture is triggered when the outflow to the lumen is occluded by various circumstances such as low fiber intake, fecaliths, however, the reasons are varied depending on the group and risk factor. There is genetical association found on $4 \mathrm{q} 25$ locus, which translates into the PITX2 protein for acute appendicitis in its variant rs2129979 in adult patients from the Netherlands and Iceland. [3] 


\subsection{Clinical Picture}

Atypical clinical presentation is due to altered or modified anatomical presentations such as: pregnancy, abnormally long appendix with avocation to the right iliac fossa, subhepatic location, situs inversus; generating epigastralgia, cramp-like periumbilical pain with no improvement in bowel movements, absence of anorexia, pain in the right hypochondrium; they are risk factors for developing complications from appendicitis.[4]

Appendicolith is the most common etiologic factor of appendiceal intestinal obstruction in $32 \%$ of cases in adults, followed by lymphoid hyperplasia as a cause in pediatric patients [5].The Alvarado scale and RIPASA can provide objectivity to calculate the probability of appendicitis, the RIPASA scale has a positive advantage in terms of sensitivity, with the inversely proportional disadvantage in terms of its specificity compared to the Alvarado scale. $[6,7]$

The mean platelet volume (MVP) is currently considered as an acute phase reactant, it is considered an indicator inversely proportional to the process of systemic inflammatory response and directly proportional to a chronic disease if an increase in the upper limit of its usual range is detected. Therefore, it has been promoted as a biomarker-type study object with great diagnostic and prognostic potential for AA processes with sensitivity of $83.7 \%$ and specificity $23.21 \%$. [8, 9]

Currently, the non-existence of a biomarker with statistical utility that surpasses other biomarkers, such as:C-reactive protein, total bilirubin, Procalcitonin, IL-6; with sensitivities of $76 \%$; $51 \%, 36 \%$; $73 \%$; respective specificity of $50 \%$, $78 \%$; $88 \%$; 72\%.. Neutrophil radius has been found as an inflammatory predictor when the radius exceeds 3.5. Leukocyte count elevation is one of the biomarkers with the highest statistical significance for a complication due to acute appendicular inflammation in pediatric patients. [8]

The utility of tomography to detect perforated appendicitis is exemplified in the comparison by the histopathological report with a positive predictive value of $37 \%$, sensitivity $62.5 \%$ by Gaskil. [10]

\subsection{Treatment}

The search for alternatives for the treatment of appendicitis is already known, however it has been determined that the alternative with changes based on the antimicrobial scheme represents a higher cost in the future than that of an appendectomy, in addition, prolonged exposure generates in a future antibiotic resistance. Although it has determined some efficacy for the treatment of acute appendicitis, a 5-year follow-up was performed, in which recurrence of up to $39.1 \%$ was demonstrated, considering a future alternative for conservative treatment in patients with high surgical risk. In such cases, administered for a period of 3-5 days has been proposed as an alternative; likewise for the management of uncomplicated appendicitis cases, with a 5 year recurrence risk of 38\%. [11, 12]

Certain factors must be considered for its approach, such as age and comorbidities, this reduces the number of surgical procedures by $77 \%$, with a risk of $0.7 \%-10.7 \%$ of presenting adhesions. Being of utmost importance the discrimination of antimicrobial use by the surgeon, since it has been shown an increase in complexity to locate the appendix covered by fibrosis and subsequently a laborious dissection culminating in possible major surgical complications. [13]

Careful discrimination must be made according to the individual needs of each patient for antimicrobial stratification in the preoperative, intraoperative and postoperative periods [14]. Establishing certain parameters such as imaging findings (presence of appendicolith), the age of the patient and data on systemic inflammatory response to avoid loss of antimicrobial efficacy, in addition to pseudomembranous colitis. [15]

\section{Patients And Methods}

The study was developed retrospectively between February 2018 and February 2020, comparing Mean Platelet Volume in male patient in ages between 15-35 years old in two groups. Appendicitis group confirmed by histopathology and their control group, patients admitted for elective inguinal hernia. Values of leukocytes, neutrophils, MPV, were used for their analysis.

\subsection{Exclusion Criteria}

Files with Incomplete Data, female, younger than 15 years old, older than 35 years old, lack of histopathology confirming appendicitis and personal story of hematological disease or inmunosupresion. 
Table1. Compares the averages of the laboratory values between both population samples

\begin{tabular}{|c|c|c|c|}
\hline Category & \begin{tabular}{|l|} 
Apendicitis \\
mean \\
sample \\
\end{tabular} & $\begin{array}{l}\text { Hernia } \\
\text { mean } \\
\text { sample }\end{array}$ & P Value \\
\hline Hemoglobin & \begin{tabular}{|l|}
15.779 \\
1.1576 \\
\end{tabular} & $\begin{array}{ll}16.362 & \pm \\
0.8453 & \end{array}$ & $>0.5$ \\
\hline $\begin{array}{l}\text { White } \\
\text { bloodcellscount }\end{array}$ & \begin{tabular}{|l|}
14.618 \\
4.8827 \\
\end{tabular} & $\begin{array}{ll}6.884 & \pm \\
1.4541 & \\
\end{array}$ & 0.021 \\
\hline Neutrophils & \begin{tabular}{|l|}
12.624 \\
4.8570 \\
\end{tabular} & $\begin{array}{ll}3.987 & \pm \\
1.2746 & \end{array}$ & 0.039 \\
\hline Platelets x 109 & $\begin{array}{l}259.23 \\
61.226 \\
\end{array}$ & $\begin{array}{l}265.28 \\
65.737 \\
\end{array}$ & 0.041 \\
\hline \begin{tabular}{|l|} 
Mean \\
PlateletVolume
\end{tabular} & \begin{tabular}{|l|}
8.256 \\
0.9335
\end{tabular} & $\begin{array}{ll}9.251 & \pm \\
1.1507 & \\
\end{array}$ & 0.028 \\
\hline
\end{tabular}

\subsection{Statistical Analysis}

The database was performed and the statistical program SPSS version 23.0 for Mac IOS 10.6 was used to perform statistical data analysis. Complications, risk factors, and general characteristics were registered and compared between the groups using X2 test, with $p<.05$ indicating a significant correlation. A multivariate analysis was performed for the independent variables and the possible association with complications, all of this with a $95 \%$ interval confidence.

\section{ReSUlts}

Thirty-nine patients with a diagnosis of appendicitis with a mean age of 24.9 years with a range of 15 to 35 years were included, the control group included 40 patients with a mean age of 26.33 years with a range of 16 to 35 years. There were no significant differences between the AA and control groups with respect to age.The Alvarado scale score in 25 patients was 6-7 points, while a lower score of 5 points was observed in 14 patients.

The following values were collected from the total of patients: hemoglobin, white blood cells (WBC), Absolute Neutrophils, Platelets, Mean Platelet Volume. Table 1. compares the averages of the laboratory values between both population samples. The absolute leukocytes and neutrophils show higher values in the appendicitis group vs. the hernia group. On the other hand, the platelet value is increased in the control group

In the VPM values in the appendicitis group, an average of $8,256 \pm 0.9335$ is observed and in the control group, values of 9,251 \pm 1.1507 are observed with a statistically significant difference with $\mathrm{p}<0.05$. In this figure, a comparative graph is observed between the value of PVM in patients with appendicitis vs. the control group, observing the trends and differences in both groups. The Pearson's correlation value between the diagnosis and the VPM value was .000074, which implies that it has statistical significance between both groups, seen in Graphic 1.

\section{DISCUSSION}

Some studies suggest the best MPV level cutoff point for AA was $7.6 \mathrm{fL}$, with a sensitivity, specificity, positive predictive value (PPV), and negative predictive value (NPV) of $73 \%, 84 \%$, $84 \%$, and $74 \%$, respectively [16]

Despite the fact that most of the studies exemplify its use with statistical results, there is great controversy over whether the biomarker is elevated [17] or decreased [18-20] in acute appendicitis, generating a large discrepancy to be able to suggest it in a systematic way. There are no similar data among the multiple studies on PMV with respect to international baselines and how it is affected in the disease, so the lack of consistent and reproducible data affects the great doubt about the usefulness of this biomarker.[21, 22]

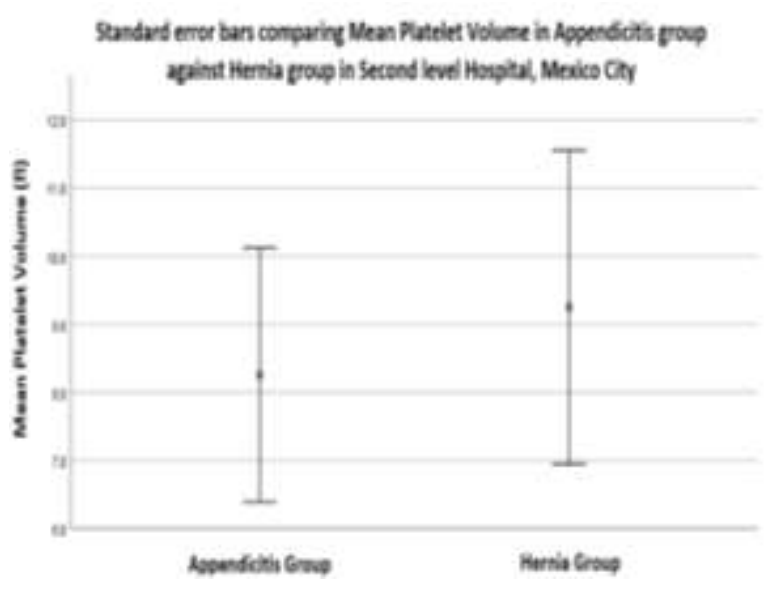

\section{ConClusions}

Although quite practical, there is insufficient evidence to recommend the systematic use od mean platelet volume as diagnostic criteria for acute appendicitis, multiples studies suggest its use with wide range sensibility. Further research is still need.

\section{CONFLICTS OF INTEREST AND FUNDING}

None

\section{ETHICAL APPROVAL}

Due to the retrospective nature of this study ethics committee approval was waived. 


\section{ACKNOWLEDGMENTS}

ToInstituto Mexicano del Seguro Social and Dra. Anota Rivera for facilitating this research within your facilities and to Dr. Rodriguez Wong for supervising the methodology and statistics in this article.

\section{REFERENCES}

[1] Wagner M, Tubre DJ, Asensio JA. Evolution and Current Trends in the Management of Acute Appendicitis. Surg Clin North Am. octubre de 2018;98(5):1005-23.

[2] Ceresoli M, Zucchi A, Allievi N, Harbi A, Pisano M, Montori G, et al. Acute appendicitis: Epidemiology, treatment and outcomesanalysis of 16544 consecutive cases. World J Gastrointest Surg. 2016;8(10):693.

[3] Kristjansson RP, Benonisdottir S, Oddsson A, Galesloot TE, Thorleifsson G, Aben KK, et al. Sequence variant at $4 \mathrm{q} 25$ near PITX2 associates with appendicitis. Sci Rep [Internet]. diciembre de 2017 [citado 26 de diciembre de 2018];7(1). Disponible en: http://www. nature.com/articles/s41598-017-03353-0

[4] Naderan M, Shahr Babaki AE, Shoar S, Mahmoodzadeh H, Nasiri S, Khorgami Z. Risk factors for the development of complicated appendicitis in adults. Turk J Surg. 22 de febrero de 2016;32(1):37-42.

[5] Khan M, Ullah H, Aziz A, Tahir M. Outcomes of Primary Unilateral Cheiloplasty in SameDay Surgical Settings. Arch Plast Surg. 15 de mayo de 2016;43(3):248-53.

[6] Alvarado A. How to improve the clinical diagnosis of acute appendicitis in resource limited settings. World J Emerg Surg [Internet]. diciembre de 2016 [citado 26 de diciembre de 2018];11(1). Disponible en: http://wjes.biomedcentral.com/articles/10.1186/ s13017-016-0071-8

[7] Frountzas M, Stergios K, Kopsini D, Schizas D, Kontzoglou K, Toutouzas K. Alvarado or RIPASA score for diagnosis of acute appendicitis? A meta-analysis of randomized trials. Int J Surg. agosto de 2018;56:307-14.

[8] Acharya A, Markar SR, Ni M, Hanna GB. Biomarkers of acute appendicitis: systematic review and cost-benefit trade-off analysis. Surg Endosc. marzo de 2017;31(3):1022-31.

[9] Toktas O, Mehmet Aslan. Mean platelet volume, red cell distribution width, neutrophil to lymphocyte ratio and platelet to lymphocyte ratio in the diagnosis of acute appendicitis. East J Med. Volume:22(January-March/2017).

[10] Gaskill CE, Simianu VV, Carnell J, Hippe DS, Bhargava P, Flum DR, et al. Use of Computed Tomography to Determine Perforation in Patients With Acute Appendicitis. Curr Probl Diagn Radiol. enero de 2018;47(1):6-9.
[11] Salminen P, Tuominen R, Paajanen H, Rautio T, Nordström P, Aarnio M, et al. Five-Year Follow-up of Antibiotic Therapy for Uncomplicated Acute Appendicitis in the APPAC Randomized Clinical Trial. JAMA. 25 de septiembre de 2018;320(12):1259.

[12] Sippola S, Grönroos J, Tuominen R, Paajanen $\mathrm{H}$, Rautio $\mathrm{T}$, Nordström $\mathrm{P}$, et al. Economic evaluation of antibiotic therapy versus appendicectomy for the treatment of uncomplicated acute appendicitis from the APPAC randomized clinical trial: Economic evaluation of antibiotic therapy versus appendicectomy for uncomplicated acute appendicitis. $\mathrm{Br} \quad \mathrm{J}$ Surg. septiembre de 2017;104(10):1355-61.

[13] Di Saverio S, Birindelli A, Kelly MD, Catena F, Weber DG, Sartelli M, et al. WSES Jerusalem guidelines for diagnosis and treatment of acute appendicitis. World J Emerg Surg [Internet]. diciembre de 2016 [citado 26 de diciembre de 2018];11(1). Disponible en: http://wjes.biomedcentral.com/articles/10.1186/ s13017-016-0090-5

[14] Lotti M. Second date appendectomy: Operating for failure of nonoperative treatment in perforated appendicitis. Am J Emerg Med. junio de 2017;35(6):939.e3-939.e6.

[15] Lietzén E, Mällinen J, Grönroos JM, Rautio T, Paajanen $\mathrm{H}$, Nordström $\mathrm{P}$, et al. Is preoperative distinction between complicated and uncomplicated acute appendicitis feasible without imaging? Surgery. septiembre de 2016;160(3):789-95.

[16] Albayrak Y, Albayrak A, Albayrak F, Yildirim R, Aylu B, Uyanik A, et al. Mean Platelet Volume: A New Predictor in Confirming Acute Appendicitis Diagnosis. Clin Appl Thromb. agosto de 2011;17(4):362-6.

[17] Narci H, Turk E, Karagulle E, Togan T, Karabulut K. The Role of Mean Platelet Volume in the Diagnosis of Acute Appendicitis: A Retrospective Case-Controlled Study. Iran Red Crescent Med J [Internet]. 5 de diciembre de 2013 [citado 25 de junio de 2020];15(12). Disponible en: https://sites. kowsarpub.com/ircmj/articles/16027.html

[18] Erdem H, Aktimur R, Cetinkunar S, Reyhan E, Gokler C, Irkorucu O, et al. Evaluation of mean platelet volume as a diagnostic biomarker in acute appendicitis. Int $\mathbf{J}$ Clin Exp Med. 2015;8(1):1291-5.

[19] Kucuk E, Kucuk I. Mean Platelet Volume is Reduced in Acute Appendicitis. Turk J Emerg Med. marzo de 2015;15(1):23-7.

[20] Dinc B, Oskay A, Dinc SE, Bas B, Tekin S. New parameter in diagnosis of acute appendicitis: platelet distribution width. World J Gastroenterol. 14 de febrero de 2015;21(6):1821-6. 
[21] Fan Z, Pan J, Zhang Y, Wang Z, Zhu M, Yang $B$, et al. Mean Platelet Volume and Platelet Distribution Width as Markers in the Diagnosis of Acute Gangrenous Appendicitis. Dis Markers. 2015;2015:1-4.
[22] Madani S, Tarlan M, Mozafari H, Khazaei S, Shaveisi-Zadeh F, Mozafari S. Role of platelet parameters as a biomarker in diagnosis of acute appendicitis: A retrospective case-controlled study. J Acute Dis. 2019;8(4):153.

Citation: Alberto Robles Méndez Hernández, Ulises Rodríguez Wong, Gilberto Gerardo Ortiz Cantú, Jorge Alfonso Pérez Castro y Vázquez, Carlos Eduardo Rodríguez Rodríguez, Adriana Paz Mendoza, Samantha Escorza Valdivia, María Anota Rivera. Mean Platelet Volume in Acute Appendicitis a Case-Control Study. ARC Journal of Surgery. 2020; 6(1):16-20. DOI: https://doi.org/ 10.20431/2455-572X.0601005.

Copyright: (C) 2020 Authors. This is an open-access article distributed under the terms of the Creative Commons Attribution License, which permits unrestricted use, distribution, and reproduction in any medium, provided the original author and source are credited. 